\title{
The Status Quo and Countermeasures of Graduation Design for Engineering Colleges
}

\author{
Qing SUN \\ Air Force Engineering University \\ Xi'an, China \\ sunqing2002@126.com
}

\author{
Qiliang ZHANG \\ Air Force Engineering University \\ Xi'an, China
}

\begin{abstract}
The quality of graduation design is an important indicator to measure the success or failure of undergraduate education. The paper analyzed the graduation design status of engineering colleges and the factors that affect the quality of undergraduate thesis, and put forward effective strategies to improve the undergraduate thesis.
\end{abstract}

Keywords-graduation design; problems; current situation; countermeasures

\section{INTRODUCTION}

The teaching process of graduation design for engineering students in colleges and universities is an important means to achieve the training objectives, and it is conducive to the cultivation of students' comprehensive qualities and the ability to investigate and research, design, preliminary research and innovation. It will lay a good foundation for graduates to go into work posts and adapt to the standardized management of teaching, scientific research and production. However, it is worth causing deep thought that management in some colleges and universities during the graduation design stage is confusion, and the quality of the student's graduation thesis completion is poor, which leads to the graduation design flow in the form.

\section{Analysis of Graduation Design Status OF ENGINEERING COLLEGES}

Current situations that we are unwilling to see appear in some colleges and universities. The main reason is the management system problems, and we can't simply blame that the students are not serious and the teachers are not dedicated, but many kinds of objective situations made it, such as the employment pressure of students, social employment-oriented, disproportionate workload and treatment of teachers', insufficient scientific and normative management work and so on.

\section{A. Students' attitudes to graduation design}

Firstly, some students are not interested in graduation design. In the aspect of design title assignment, teachers provide a number of topics, and the competent department uses some kind of method to forcibly assign to the students without considering the interest of the students, which causes some students to have an indifferent attitude towards graduation design; secondly, due to the high employment pressure, some students are busy Looking for jobs or going to the workplace for trial, which causes insufficient investment in graduation design. Thirdly, the management of graduation design is loose. Near graduation, colleges will pay more attention to the students' management than to the graduation process, which will lead to the result that some students can't complete the design tasks required by the schedule, and even plagiarism.

\section{B. Selected topics for graduation design}

The topic selection is always with high positioning. Graduation design should be positioned at the stage of study. Therefore, it should satisfy the teaching requirements firstly. Through this link, students can be exercised and trained comprehensively. However, some teachers are used to positioning too high, and it is difficult for the students to complete the tasks during graduation design, which will dampen the students' enthusiasm to some extent. The theoretical and practical aspects of graduation design topics are not uniform. In the previous few years, most of the graduation designs were limited to theoretical research. After graduation design, the research results were shelved and were rarely used to guide work and practice, so that students thought they were doing nothing during the period.

\section{Performance of instructors}

A very small number of teachers lack responsibility. They do insufficient guidance, and pay little attention to the students After arranging the topics, students are not instructed or supervised appropriately and timely.

The issue of graduation design for college undergraduates has attracted the attention of some knowledgeable. Some even suggested canceling the undergraduate thesis. This view is too extreme. The function of undergraduate graduation should be fully and correctly viewed, and we should do something to make this part have a real training effect.

\section{ANALYSIS TO THE FACTORS THAT AFFECT THE QUALITY OF UNDERGRADUATE THESIS}

From the investigation and analysis, the quality of undergraduate thesis is not satisfactory at present. There are mainly internal and external influence factors. The main internal reasons are students' problems in theoretical study, method mastery, and cognitive attitude. The external causes 
are mainly the leak existing in the environment and regulatory mechanisms.

\section{A. Lack of in-depth study in basic theory}

Because of the lack of in-depth study in basic theories, many students are unable to start with the vast literature, and will not use the knowledge they have learned to analyze and refine the literature, and put forward unique ideas. In many students' open-ended reports and literature review materials, problems are ubiquitous, such as the status quo of research on the topic is often unclear, the purpose is not clear, the literature is improperly summarized, the advantages and disadvantages of the literature cannot be explained, the contents of the research cannot be elaborated and so on. The existence of these problems is due to students' lack of understanding to the basic knowledge and theory of the discipline.

\section{B. Lack of mastery to the professional methods}

Many students do not understand professional methods, and not to mention master them proficiently, which will result in low quality of the papers they write. First of all, they do not understand the method of writing the dissertation. They do not know that the writing of the dissertation must follow a certain logical sequence and relatively fixed format requirements. Secondly, they are unfamiliar with the professional research methods required by the disciplines, resulting in the lack of representation, authenticity and accuracy to the collected data, or research methods are not closely related to the research subject. In fact, some undergraduates do not have a good grasp of the analytical methods in engineering studies. They can't go deep into the investigation and can't get meaningful materials. This lack of mastery of the disciplines and professional methods causes the dissertation to be written with no realistic meaning or academic significance.

\section{The Vague Cognition to the Graduation Thesis}

Some students have unclear understanding to the role and value of graduation thesis, and they process perfunctory attitude in thesis writing. This will lead to an unreasonable schedule of graduation thesis, a serious plagiarism, and even a particularly evident psychological in coping writing. This kind of erroneous cognition to the dissertation causes some students to pay very little attention to the dissertation. They don't read the related literature materials before writing, their selected topics have no practical significance and theoretical value, they don't want to think deeply during the writing process, and they devote less time to writing. After writing, they will do little changes work, and some even copy and paste directly from the Internet or other articles. The lack of understanding to the importance of graduation thesis and the unfair attitude of writing lead to many theses lacking theoretical value and practical significance.。

\section{Impact of external environment}

Another influencing factor for the quality of undergraduate thesis is the influence of external hard and soft environment, which is manifested in the institutions' lax requirements on undergraduate thesis, social reemployment dissertation and guidance teachers' enthusiasm. First of all, some institutions make low requirements for undergraduates' dissertations, and there are even no punitive measures for non-compliant dissertations. Secondly, because the values of the whole society are measured by economic criteria, the society generally values the situation of undergraduates in terms of employment, advanced studies or going abroad. These things take a lot of time and effort for graduates and directly cause graduates to spend insufficient time in the paper. There is no inevitable connection between graduation thesis and employment, and which will influence many students to take a negative attitude towards their own thesis. Finally, the enthusiasm of teachers is not enough. Most teachers originally have both teaching tasks and scientific research tasks. They also have to direct the graduation thesis throughout the course. With the expansion of enrollment in colleges and universities, the number of graduation projects that each teacher instructs is excessive, and the workload of the thesis guidance will increase teacher's work pressure and mental stress, result in negative psychology, and thus will lead to lacking of enthusiasm.

\section{E. The unsound supervision mechanism}

The incompleteness of the supervision, management and inspection mechanism for graduation design is another important reason for the low quality of graduation thesis. The thesis writing should be an important part of the teaching content. It is a systematic project that contains many details, which need to be managed from every links and to be valued from every step and detail by teachers and institutions. Institutions should formulate rules and regulations for guaranteeing the quality of graduation thesis from the macro level and ensure the implementation, and the whole process of thesis writing should be tracked and supervised. Teachers should guide and check students' graduation thesis on a microscopic level to process one-on-one services, and to grasp the learning dynamics, ideological trends and writing dynamics. This will establish a top-down comparative system and a complete evaluation mechanism to ensure the quality of undergraduate thesis.

\section{EFFECTIVE STRATEGIES OF IMPROVING THE UNDERGRADUATE THESIS}

Based on the above issues, we are tapping the teaching potential, formulating effective strategies, exploring management ideas, and striving to find new ways to improve the quality of thesis.

\section{A. Strengthening Quality Consciousness is the key to improving thesis quality.}

The dissertation is not only a test of student's four-year learning achievement, innovation ability and comprehensive quality, but also a comprehensive examination of the teacher's four-year teaching quality. First of all, it is necessary to establish a high degree of quality awareness and responsibility among the leaders and teachers of institutions. A profound understanding of this task is the key to improving the level of institution's management and teaching standards, and is an important basis for cultivating high-quality personnel. 
Secondly, we must deploy meticulously and plan carefully to come up with practical and feasible plans and measures so as to ensure the effective quality of the papers, and we must form a good situation that the institution leaders and the professional tutors are co-opted together.

\section{1) Requirements for instructors}

Instructors who independently guide graduation design should have a middle or intermediate level or higher title. According to their applications, the teaching assistants may be arranged to participate in a tutor group to help guiding the graduation design. The instructor should prepare the graduation project title and related materials carefully, determine the quality requirements and progress of the design work, prepare the graduation design work plan, perform the report title, complete the graduation design task book and other work conscientiously. The instructor should specifically guide students in their research, reviewing literature, using reference books, processing computers for design, experiment and data processing, translating, data collecting, papers writing and so on. Teaching and educating is the sacred duty of teachers. Instructors should pay attention to cultivating students' rigorous work style and strict meticulous work attitude during graduation design.

\section{2) Requirements for Students}

Students should complete graduation design tasks independently. In the graduation design process, they must have rigorous work style, practical and realistic attitude and meticulous work attitude. No plagiarism or falsification may be allowed. Students should respect the instructors, consult with the instructor in an open mind, and take the initiative to accept the instructor's check at any time. Students in the graduation design must strictly abide by the discipline, obey the leadership, love the equipment, and comply with the operating procedures and various rules and regulations.

\section{3) Requirements for the graduation design title}

Graduation design should start from the goal of personnel training. Instructors should choose the subject combined with the actual project as far as possible, or combined with the construction of the laboratory or related courses. As to different professional orientations, graduation design topics should have different emphasis. The specific requirements should be explained in the graduation design guidance book. The selection of graduation project topics should be based on the actual level of the students', topics with appropriate research content are allowed to ensure that students can accomplish their tasks within the required time and effort.

\section{B. The scientific plan is a precondition for improving the quality of thesis.}

As the study, examinations, postgraduates, education internships, employment and thesis writing are often intertwined, and the quality of the thesis will be seriously affected. We can adopt a way to lengthen the work of graduation thesis, handle conflicts scientifically, and advance the graduation thesis design work to the middle of the seventh semester. We will first discuss and determine the content of one discipline in various subject instructors, collect the topics for the thesis, and fill in the Thesis Selection Table to be issued, and then adapt the approach of double selection between instructors and students to determine the instructor and complete the selection process. Under the guidance of instructors, students are allowed to collect and read relevant documents, write opening report, and complete an outline. During the winter break, students can further comb the theory ideas, keep in touch with instructors through e-mail, and write the first draft. This will not only ensure the guidance of instructors, but also give students sufficient time to perfect thesis.

\section{Strengthening management is an important means to improve the quality of thesis.}

It is an urgent task to fully improve teaching management and teaching quality that strengthening scientific management to graduation thesis work and institutionalizing the writing process. We can formulate a systematic Detailed Implementation Regulation for Undergraduate Thesis which includes guiding principles, graduation thesis requirements, links and timetable for graduation thesis, principles and requirements for selection of topics, requirements for instructors and students, review rules and so on, which will make specific and standardized measures and will supply a rule for the management of graduation thesis work has to follow. At the same time, we should pay great attention to the management of graduation thesis process, and effectively grasp the topics selection, opening thesis, mid-term examination, thesis review, dissertation defense and scoring. Practice has proved that a sound management system plays an important guiding role in the work of graduation thesis.

\section{Formulate measures on inspection of paper quality and review, and strictly control the quality of the paper.}

In order to ensure the quality of students' thesis, we use open questions, mid-term examinations, and pre-answers as means of quality control, understand the progress of the students' papers and guidance of the teachers in time to ensure that the thesis guidance work is in place, and we scientifically stipulate and strictly operate the reply procedure, The defense procedure fully guarantees that the process of assessing the graduation thesis conforms to the principle of fairness and justice, strict requirements, and improved quality, so that the results of the dissertation are fundamentally guaranteed.

\section{CONCLUSION}

Practice has proved that the quality of graduation thesis has been significantly improved by strengthen the systematic and scientific management of graduation thesis. First of all, the teachers' and students' consciousness has been improved, and so that the quality of graduation thesis writing and defense has been improved and the intended purpose has been achieved. Secondly, in the process of designing and writing a graduation thesis, the students' knowledge has been comprehensively applied. The ability to innovating awareness, analyzing problems and solving problems, reading literature materials, and translating information has been greatly improved. And at the same time, it also provides students with the opportunity to show off their talents, thus ensuring the quality of the dissertation. Finally, teachers' emphasis on this teaching link 
has been strengthened, teachers' enthusiasm to guide the graduation thesis has been enhanced, and the teaching profession has grown to explore a new way of pursuing a thesis work.

\section{REFERENCES}

[1] HUANG Chunmei. Undergraduate Graduation Thesis Not to Be Cancelled---A Survey of Graduation Thesis Writing in Four Universities in Wuhan[J].Journal of ZHUZHOU Teachers College,Vo.l12,2007.(In Chinese)

[2] YANG Mei. Research on the Current Teaching Situation and Countermeasures of Undergraduate Thesis Writing in Colleges and Universities[J],Shaanxi Education,Vol.9,2012(In Chinese)
[3] SHI Wei. Abandonment and Preservation of Undergraduate Thesis[J]. Higher education in China.2010,(7):45-47. (In Chinese)

[4] HE Ling, WANG Xiping, YANG Ronghui. Analysis of the Status of Undergraduate Thesis and Countermeasures[J].Education Teaching Forum,No.48,Nov.2014. (In Chinese)

[5] SUN Yi, LIU Xiongfei, DENG Gaige. Research on the Innovation of Graduation Design in Application-oriented Universities Education Teaching Forum[J],Vol48,2016. (In Chinese)

[6] LI Hongwei.Problems and Countermeasures of University Thesis Writing-A Case Study of Comparative Literature Thesis Writing of Chinese Language and Literature Majors at W University in Beijing. Journal of Research on Education for Ethnic Minorities[J], Vol24,No.5,2013. (In Chinese)

[7] LIYan, ZHANG Ming, ZHOU Tengjiao.The problems existing in the undergraduate course graduation thesis writing and countermeasures research[J], Wisdom, 2018(06). (In Chinese) 